\title{
Simulated impact of urban expansion on future temperature heatwaves in Sydney
}

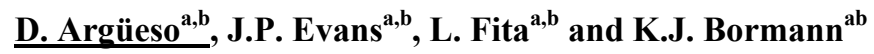 \\ ${ }^{a}$ Climate Change Research Centre and University of New South Wales, Australia. \\ ${ }^{b}$ ARC Centre of Excellence for Climate System Science, University of New South Wales, Australia. \\ Email:d.argueso@unsw.edu.au
}

\begin{abstract}
The combined effect of climate change and urbanisation on 2-m temperature are investigated over Greater Sydney using the Weather Research and Forecasting (WRF) model. The climate of the region is simulated at $2 \mathrm{~km}$ horizontal spatial resolution for the present (1990-2009) and a possible future (2040-2059) climate scenario (following the A2 emission scenario). The model default land use is replaced with a more accurate dataset that covers the Sydney area, which also includes the expected urban expansion in the future simulation according to local government urbanisation plans. The areas with projected land use changes are identified and compared with the rest of the region to evaluate how urban expansion and global warming will act together on the persistence of warm conditions.

Larger heat capacity of urban structures and inhibited evaporation by impervious surfaces are responsible for changes in the surface energy flux partition, which in turn affect near-surface temperature. In addition to changes driven by climate change alone, future urbanisation will greatly affect minimum temperature, and thus nighttime heatwaves. The urbanisation footprint on minimum temperatures is noticeable throughout the year but it is particularly strong during winter and spring, when the differences with the surroundings are especially marked. Daytime heatwaves are also projected to increase over Greater Sydney, with larger changes over the interior, but urban expansion has no perceptible impact on the occurrence of maximum temperature heatwaves, which suggests that the changes are caused by climate change alone.
\end{abstract}

Seasonal differences for each of the temperature daily extremes, as well as between maximum and minimum temperature, are partly explained by the prevalent direction of winds that compensate or intensify the effect urbanisation on local temperatures.

Keywords: Regional climate, climate models, temperature, urbanisation 


\section{INTRODUCTION}

The effects of urbanisation on local climate have drawn scientists' attention for well over a century, since the first study about temperature differences between urban and rural areas was conducted (Howard, 1833). The exponential growth of urban population, which currently amounts to more than half of the total world population, has conferred a particular interest on urban climate in the last few decades (Arnfield, 2003; Grimmond, 2006). The prospects of larger cities and higher percentage of urban population (UN World Population Prospects, 2012) have further increased the importance given to urban climate and the liveability of the urban environment.

Urban structures can affect local climate in various ways such as changes in aerosols, humidity or surface runoff (IPCC, 2001). However, the most prominent effect of urbanisation is the relative warmth of the cities with respect to their rural counterparts. The processes that lead to this relative warmth are usually encompassed in the widespread term 'Urban Heat Island' (UHI), which is generally defined using nearsurface temperature. This is primarily caused by higher heat capacity of the cities, inhibition of evaporative cooling by urban surfaces and reduction of the sky view factor by the so-called urban canyon. Other factors such as the anthropogenic heat release by road traffic or industries also contribute to the intensification of the UHI (Childs and Raman, 2005; Shahmohamadi et al., 2011). The prime mechanisms that generate and develop the UHI have already been identified and studied thoroughly using very different approaches (Mirzaei and Haghighat, 2010). However, not only will urban expansion determine changes in the future climate of our cities, but also global warming caused by greenhouse gases (GHGs) is to play a crucial role in shape the future urban climate. How both effects will act together in the future has been addressed from a global perspective (McCarthy et al., 2010), but many of the processes that define the urban climate occur at scales that require higher spatial resolution models to be resolved.

The primary source of future climate change information is the Global Climate Models (GCMs), which are typically run at resolutions of $200 \mathrm{~km}$ or coarser. The computational costs associated with increasing GCMs spatial resolution is currently prohibitive and alternative approaches, known as 'downscaling' techniques, have been proposed to resolve finer scale processes. Two main categories of downscaling have been put forward: statistical and dynamical downscaling. Statistical downscaling consists in establishing statistical relationships between large scale and local scale variables. On the other hand, dynamical downscaling lies in the use of Regional Climate Models (RCMs) to approximate of the numerical equations that describe the atmosphere with increased resolution over a limited region and using large scale information from GCMs as boundary conditions (e.g. Zaitchik et al., 2007a,b; Evans, 2010). Both techniques have their own benefits and shortcomings, and each of them is suited to different kind of applications. The study of the impact on climate of land use changes under future global warming conditions warrants the high computational costs of dynamical downscaling experiments, because they provide a wide range of physically consistent atmospheric variables and thus constitutes a unique tool to gain insight into the processes occurring when both phenomena act together.

A few recent studies (Argüeso et al., 2013; Georgescu et al., 2012; Kusaka et al., 2012) tackled the issue of temperature changes due to urbanisation and climate change using RCMs. Most of them selected the Weather Research and Forecasting (WRF) model (Skamarock et al., 2009) to simulate present and future climate, integrating both future emission scenarios and projected urban expansions in various cities across the world. WRF is a numerical weather prediction system designed for operational forecasting and atmospheric research that has been widely employed in a range of climate studies (e.g. Feng et al., 2012; Soares et al., 2012; Vautard et al., 2013), which showed the model capabilities to produce high-resolution climate simulations in locations with very different climate characteristics. Furthermore, an urban canopy model (Kusaka et al., 2001) was also made in the model to incorporate the effects of urbanized areas through urban physics parameterizations.

In this paper, the WRF model was adopted to simulate the present and future climate over Greater Sydney. The projected changes in temperature were investigated to determine the combined effect of urban expansion and climate change on the occurrence of heatwaves. Not only was maximum temperature used to characterize the projected changes in heatwaves or warm spells, but also minimum temperature because it has been shown that the occurrence of especially warm nights is a factor of major importance in terms of health impacts (Meehl and Tebaldi, 2004).

\section{METHODOLOGY}

The Advance Research WRF (ARW) version 3.3.1 was used to downscale the large scale information provided by the CSIRO Mk3.5 GCM (Gordon et al., 2010) over southeastern Australia. The model was 
configured following a series of studies that evaluated its performance over the region (Argüeso et al., 2013; Evans and McCabe, 2010; Evans and Westra, 2012; Evans et al., 2011) and validated its ability to describe important features of the region climate. The climate of Greater Sydney was simulated at 2-km horizontal resolution as shown in Figure 1a. The model was run over this domain for two 20-yr periods representing the present climate (1990-2009) and a possible future climate (2040-2059) under A2 emission scenario conditions from the Special Report on Emissions Scenarios (SRES, Nakicenovic et al., 2000). The boundary conditions were obtained from a previous WRF experiment (Evans and McCabe, 2010) over southeast Australia that comprised two domains at 50- and 10-km resolution (Figure 1a).
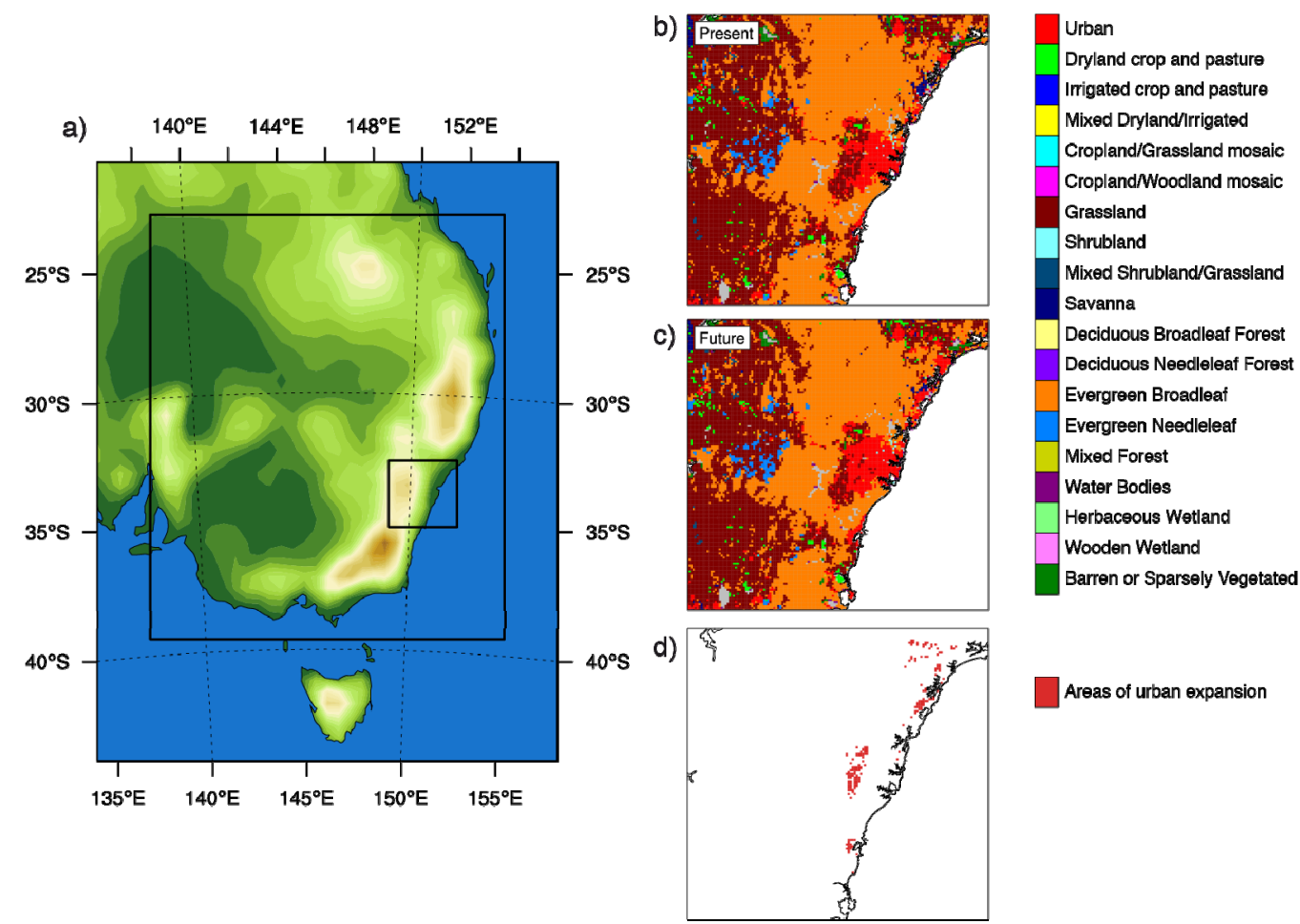

Figure 1. a Domains of the regional climate model over southeastern Australia. The map covers the 50-km domain, and the black rectangles represent the 10-km and the 2-km domains. b-c Dominant land-use category from the NSW Office of Environment and Heritage $(\mathrm{OEH})$ dataset for the present and the future. d Areas of projected urban expansion.

In order to include the effect of urbanisation in the model, the urban canopy model was switched on and the WRF default land use dataset was replaced with a more accurate one provided by the Office of Environment and Heritage (OEH) of the New South Wales (NSW) state government. Not only does the new dataset better represent the actual land use of the region, it also contains information on the projected urban expansion by 2050 according to the NSW Department of Planning, which plans future urban development and consolidation. Present and future land use configurations are illustrated in Figures 1b-c along with the differences between them shown in Figure 1d.

The observational gridded dataset from the Australian Water Availability Project (AWAP) was employed to evaluate and bias correct the model temperature using a methodology based on Piani et al. (2010). The model performance is thus assessed in terms of the near-surface temperature daily extremes and the model systematic errors are reduced to better match the observed climate features as described in Argüeso et al. (2013). The AWAP temperature products were also selected to provide a reference of the current frequency of heatwaves or warm spells. Both terms are usually interchanged and used to describe particular warm and persistent conditions. In this paper, they are also used indifferently. These were calculated following the Bureau of Meteorology's definition, which is 'any period of at least 3 consecutive days with temperature above the $90^{\text {th }}$ percentile of the corresponding calendar month'. Using daily temperature extremes it is possible to characterize two kinds of heatwaves based on maximum and minimum temperature, which might have very different repercussions. 


\section{RESULTS}

Temperature is affected differently by urbanisation throughout the day and the seasons, and so are the future projected changes in the new urban areas, as shown in Argüeso et al. (2013). Maximum and minimum temperature heatwave changes are examined at seasonal scales to determine whether this pattern is also present in the occurrence of persistent warm conditions.

Figure 2 illustrates the present climate (1990-2009) frequency of heatwaves at seasonal scales from AWAP maximum temperature (Tmax) and the projected changes from WRF simulations. Present-day frequency of Tmax heatwaves range from 0.2 to 0.7 heatwaves month ${ }^{-1}$ in most of the Greater Sydney area, with higher values towards the interior and lower ones along the coast. According to WRF simulations, the region is projected to experience a general increase in the frequency of Tmax heatwaves, especially during the winter when the changes could exceed 1.0 heatwave month $^{-1}$ in some areas. The projected changes also indicated that climate change will increase the spatial gradient in the occurrence of Tmax heatwaves, since the largest changes are expected to occur in the interior. However, there is no signal of urbanisation in the changes of Tmax heatwaves, and climate change seems to be solely responsible for the increases.

a) AWAP
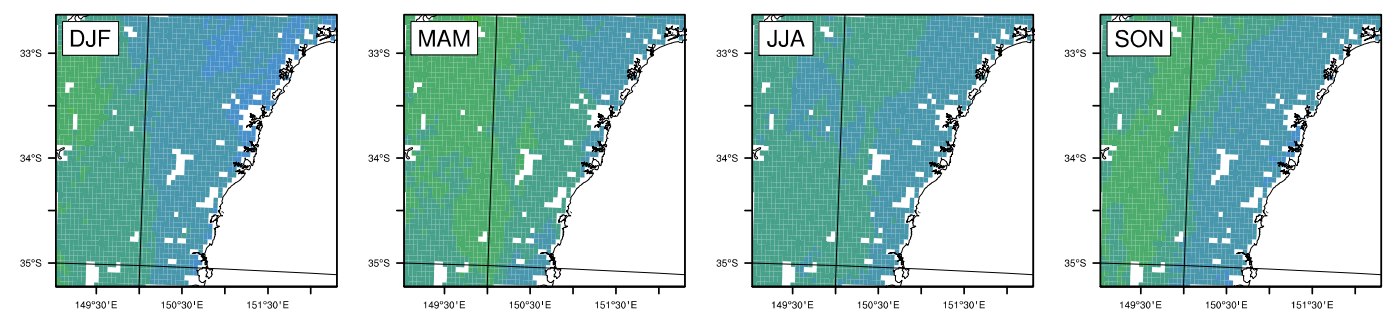

b) WRF Changes
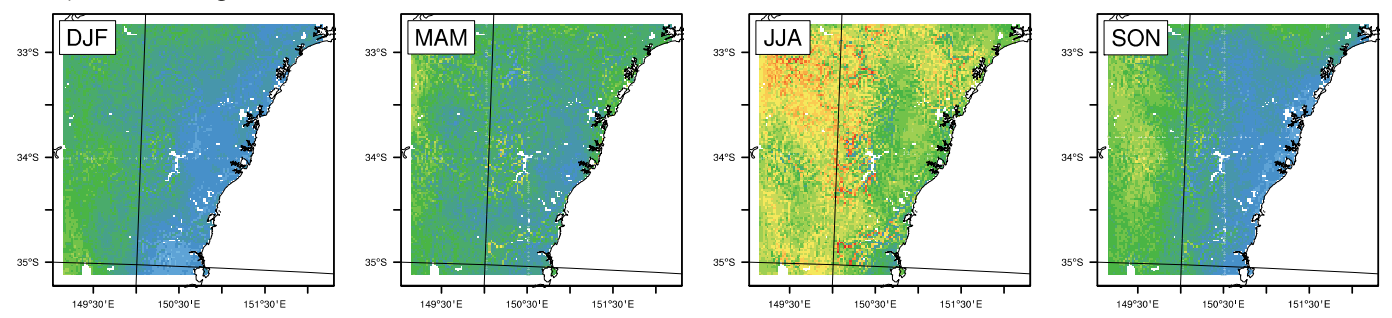

heatwaves/month

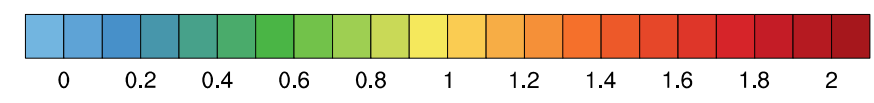

Figure 2. a Present climate seasonal frequencies of maximum temperature heat waves from AWAP (19902009). b Projected changes in seasonal frequencies of maximum temperature heat waves from WRF (20402059 vs. 1990-2009). A heat wave is defined as a period of at least 3 consecutive days with maximum temperature above the $90^{\text {th }}$ percentile of the corresponding calendar month.

On the other hand, an evident footprint of urban expansion was obtained for changes in Tmin heatwave frequencies throughout the year (Figure 3). The occurrence of Tmin heatwaves in present-day climate presents a more spatially homogeneous pattern with values that are within the 0.1-0.7 heatwaves month ${ }^{-1}$ range and larger during autumn. The changes are also projected to be overall larger during autumn, when most of the region will undergo an increase of 0.6 heatwaves month ${ }^{-1}$. Unlike Tmax, Tmin heatwaves could increase up to 2.0 heatwaves month ${ }^{-1}$ in new urban areas for most of the seasons, except summer. Indeed the increases in the new urban areas is very similar and large throughout the year, except for summer, when the minimum temperature heatwaves over the areas of urban expansion will increase their occurrence by about 1.2 heatwaves month ${ }^{-1}$.

The analysis of the prevalent winds could partially explain the seasonal, as well as the daily differences. Figure 4 shows the climatological winds at two different hours of the day that could be considered as characteristics of the time when minimum and maximum temperature are reached. During summer, prevalent winds are coming from the ocean both during the afternoon and early morning, which brings moisture and 
milder temperatures compensating for the urbanisation effect. However, in winter there is a clear difference throughout the day and early morning winds tend to come from the continent enhancing the UHI effect, whereas afternoon winds are very weak a do not contribute to the UHI effect.

a) AWAP


b) WRF Changes
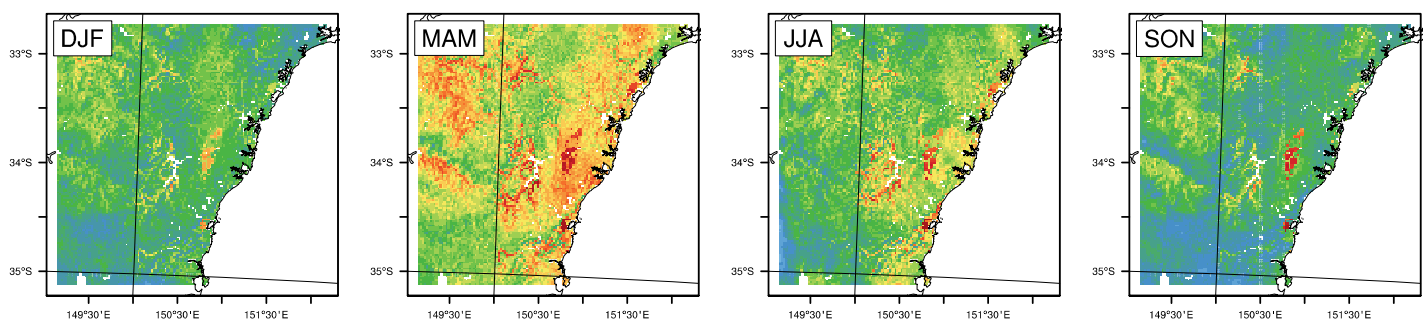

heatwaves/month

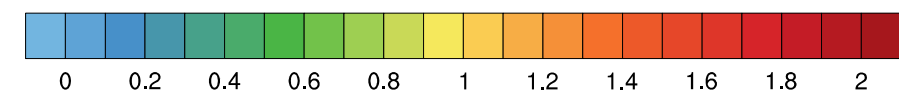

Figure 3. As Figure 2 but for minimum temperature.
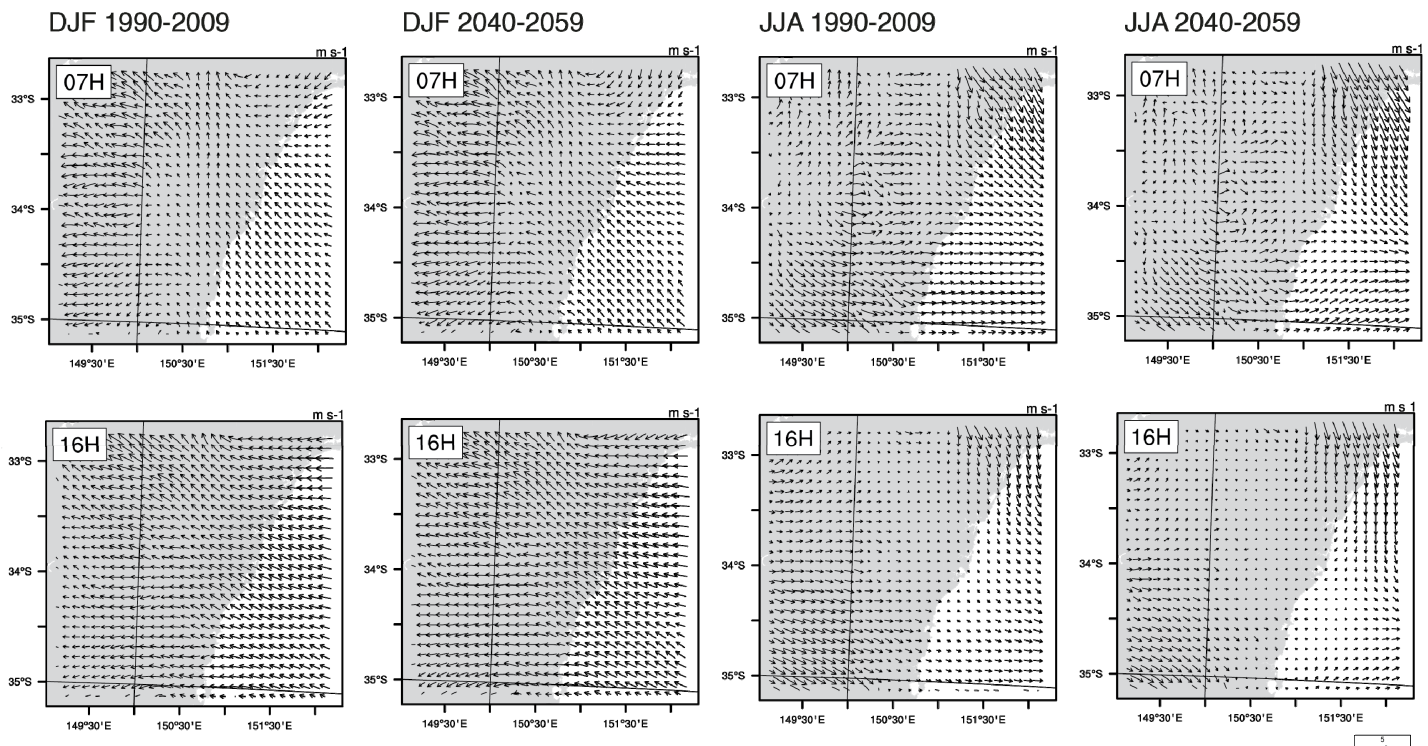

Figure 4. Climatological winds at $7 \mathrm{H}$ (top row) and $16 \mathrm{H}$ (bottom row) for present and future DJF and JJA (in columns). 


\section{CONCLUSIONS}

Both maximum and minimum temperature heatwaves in Greater Sydney are projected to substantially increase in the future due to climate change. In particular, these changes are expected to be larger during winter (JJA) for Tmax and autumn (MAM) for Tmin, although heatwaves are projected to be more frequent throughout the year.

Urbanisation has a marked impact on minimum temperature heatwaves changes, which will be significantly more frequent in the future in areas where the city is expected to grow, especially during autumn, winter and spring. No footprint of urban expansion is observed in maximum temperature heatwave changes and thus the increases in frequency are due to climate change alone according to the model.

Seasonal differences are partly explained by the direction of dominant winds, which could offset or enhance the urbanisation effect depending on whether it comes from the ocean or the continent.

\section{ACKNOWLEDGMENTS}

The NSW Environment Trust (RM08603), as well as the NSW Office of Environment and Heritage, and the Australian Research Council as part of the Future Fellowship FT110100576 and the ARC Centre of Excellence for Climate System Science, funded this study. This work was supported by an award under the Merit Allocation Scheme in the NCI National Facility at the ANU.

\section{REFERENCES}

Argüeso D, Evans JP, Fita L and Bormann KJ (2013) Temperature response to future urbanization and climate change. Climate Dynamics: doi:10.1007/s00382-013-1789-6.

Arnfield AJ (2003) Two decades of urban climate research: a review of turbulence, exchanges of energy and water, and the urban heat island. International Journal of Climatology 23(1): 1-26: doi:10.1002/joc.859.

Childs PP and Raman S (2005) Observations and Numerical Simulations of Urban Heat Island and Sea Breeze Circulations over New York City. Pure and Applied Geophysics 162(10): 1955-1980: doi:10.1007/s00024-005-2700-0.

Evans, J. P. (2010), Global warming impact on the dominant precipitation processes in the Middle East, Theoretical and Applied Climatology, 99(3-4), 389-402.

Evans JP and McCabe M (2010) Regional climate simulation over Australia's Murray Darling basin: A multitemporal assessment. Journal of Geophysical Research 115(D14114): doi:10.1029/2010JD013816.

Evans JP and Westra S (2012) Investigating the Mechanisms of Diurnal Rainfall Variability Using a Regional Climate Model. Journal of Climate 25(20): 7232-7247: doi:10.1175/JCLI-D-11-00616.1.

Evans JP, Ekström M and Ji F (2011) Evaluating the performance of a WRF physics ensemble over SouthEast Australia. Climate Dynamics.

Feng J-M, Wang Y-L, Ma Z-G and Liu Y-H (2012) Simulating the Regional Impacts of Urbanization and Anthropogenic Heat Release on Climate across China. Journal of Climate 25(20): 7187-7203: doi:10.1175/JCLI-D-11-00333.1.

Georgescu M, Moustaoui M, Mahalov A and Dudhia J (2012) Summer-time climate impacts of projected megapolitan expansion in Arizona. Nature Climate Change: doi:10.1038/nclimate1656.

Gordon H, O'Farrel S, Collier M, Dix M, Rotstayn L, Kowalczyk E, et al. (2010) The CSIRO Mk3.5 Climate Model. CAWCR Technical Report No. 021 1-74.

Grimmond CSB (2006) Progress in measuring and observing the urban atmosphere. Theoretical and Applied Climatology 84(1-3): 3-22: doi:10.1007/s00704-005-0140-5. 
Argüeso et al., Simulated impact of urban expansion on future Sydney temperature

Howard L (1833) The climate of London deduced from meteorological observations made in the metropolis and at various places around it. London: Harvey and Darton.

IPCC (2001) Climate Change 2001: The Scientific Basis. Contribution of Working Group I to the Third Assessment Report of the Intergovernmental Panel on Climate Change. [Houghton, J.T., Y. Ding, D.J. Griggs, M. Noguer, P.J. van der Linden, X. Dai, K. Maskell, and C.A. Johnson (eds.)]. Cambridge University Press, Cambridge, United Kingdom and New York, NY, USA.

Kusaka H, HARA M and Takane Y (2012) Urban Climate Projection by the WRF Model at 3-km Horizontal Grid Increment: Dynamical Downscaling and Predicting Heat Stress in the 2070's August for Tokyo, Osaka, and Nagoya Metropolises. Journal of the Meteorological Society of Japan 90B(0): 47-63: doi:10.2151/jmsj.2012-B04.

Kusaka H, Kondo H, Kikegawa Y and Kimura F (2001) A simple single-layer urban canopy model for atmospheric models: Comparison with multi-layer and slab models. Boundary-Layer Meteorology. Springer 101(3): 329-358.

McCarthy MP, Best MJ and Betts RA (2010) Climate change in cities due to global warming and urban effects. Geophysical Research Letters 37(9): doi:10.1029/2010GL042845.

Meehl GA and Tebaldi C (2004) More Intense, More Frequent, and Longer Lasting Heat Waves in the 21st Century, Science. 305: (2004) 994-997.

Mirzaei PA and Haghighat F (2010) Approaches to study Urban Heat Island - Abilities and limitations. Building and Environment. Elsevier Ltd 45(10): 2192-2201: doi:10.1016/j.buildenv.2010.04.001.

Nakicenovic N, Alcamo J, Davis G, de Vries B, Fenhann J, Gaffin S, et al. (2000) Special Report on Emissions Scenarios. International Panel on Climate Change (IPCC).

Piani C, Haerter J and Coppola E (2010) Statistical bias correction for daily precipitation in regional climate models over Europe. Theoretical and Applied Climatology 99(1): 187-192.

Shahmohamadi P, Che-Ani AI, Maulud KNA, Tawil NM and Abdullah NAG (2011) The Impact of Anthropogenic Heat on Formation of Urban Heat Island and Energy Consumption Balance. Urban Studies Research 2011: 1-9: doi:10.1155/2011/497524.

Skamarock WC, Klemp JB, Dudhia J, Gill DO, barker DM, Duda MG, et al. (2009) A Description of the Advanced Research WRF Version 3. NCAR/TN-475+STR NCAR TECHNICAL NOTE 125.

Soares PMM, Cardoso RM, Miranda PMA, Medeiros J, Belo-Pereira M and Espirito-Santo F (2012) WRF high resolution dynamical downscaling of ERA-Interim for Portugal. Climate Dynamics: doi: $10.1007 / \mathrm{s} 00382-012-1315-2$.

Vautard R, Gobiet A, Jacob D, Belda M, Colette A, Déqué M, et al. (2013) The simulation of European heat waves from an ensemble of regional climate models within the EURO-CORDEX project. Climate Dynamics: doi:10.1007/s00382-013-1714-z.

World Prospects, the 2011 Revision (2012) World Prospects, the 2011 Revision. New York: United Nations Department of Economics and Social Affairs, Population Division.

Zaitchik, B. F., J. P. Evans, R. A. Geerken, and R. B. Smith (2007a), Climate and vegetation in the Middle East: Interannual variability and drought feedbacks, Journal of Climate, 20(15), 3924-3941.

Zaitchik, B. F., J. P. Evans, and R. B. Smith (2007b), Regional impact of an elevated heat source: The Zagros Plateau of Iran, Journal of Climate, 20(16), 4133-4146. 